\title{
Restrictive Infusion Therapy in Patent Ductus Arteriosus Management in Premature Infants
}

\author{
Aleksii Obolonskyi ${ }^{1}$, Olha Obolonska ${ }^{2}$, Kateryna Dereza ${ }^{1}$ \\ ${ }^{1}$ Regional Children's Hospital, Dnepr, Ukraine \\ ${ }^{2}$ Department of Pediatrics Dnepropetrovsk Medical Academy, Dnepr, Ukraine
}

Email address:

a_obolonskij@ukr.net (A. Obolonskyi), a_obolonskija@ukr.net (O. Obolonska), katrindereza83@gmail.com (K. Dereza)

To cite this article:

Aleksii Obolonskyi, Olha Obolonska, Kateryna Dereza. Restrictive Infusion Therapy in Patent Ductus Arteriosus Management in Premature Infants. American Journal of Pediatrics. Vol. 5, No. 1, 2019, pp. 22-27. doi: 10.11648/j.ajp.20190501.15

Received: November 26, 2018; Accepted: February 26, 2019; Published: March 21, 2019

\begin{abstract}
The persistence of hemodynamically significant patent ductus arteriosus (HPDA) has a great value on a short term and long term outcomes in preterm infant. There is no hesitation that PDA should be closed pharmacologically or surgically if present. The aim of the study was to establish the advisability, efficiency and safety of using different volumes of infusion in combination with COX inhibitors and to determine its effect on the timing of the HPDA closure. Retrospectively has been studied 91 preterm infants with gestational age 26-31 weeks, manifestations of respiratory distress syndrome, HPDA treated at the NICU. The research groups were representative for gestational age, gender and weight $(1205.0 \pm 435.0$ grams). The therapy of PDA closure included using of different volumes of restrictive or liberal infusion therapy (from 50 to 100 $\mathrm{ml} / \mathrm{kg} / \mathrm{day}$ ) in combination with COX inhibitors. COX inhibitors prescribed according to standard regimens: in the first 3 days - indomethacin orally in doses $0.2 / 0.1 / 0.1 \mathrm{mg} / \mathrm{kg} /$ day. If the preterm infant had symptoms of intestinal paresis (this prevented the oral administration of indomethacin). Ibuprofen administered in a three-day course in doses of $10 / 5 / 5 \mathrm{mg} / \mathrm{kg} / \mathrm{day}$ intravenously or 20/10/10 mg/kg/day in a rectal form. In all groups of preterm used a standard therapy of PDA closure. The volume of infusion therapy was restricted in the first group. Preemies received $53.5 \pm 6.4 \mathrm{ml} / \mathrm{kg} /$ day on DOL1 and 2 . From the third day increased urinary excretion, there was an increase in the amount of infusion therapy up to $63.6 \pm 5.6 \mathrm{ml} / \mathrm{kg} /$ day, and at day 5 it was raised to $89.7 \pm 6.8 \mathrm{ml} / \mathrm{kg} / \mathrm{day}$. In the second group there was no strict adherence to the restriction of the volume of infusion therapy (especially in the first 5 days), and delayed term for the PDA closure (on average at $14.55 \pm 0.56 \mathrm{DOL}$ ) associated with that fact. In the first group the limit of the volume of infusion therapy observed more clearly in the first 5 days, and the closure of the arterial duct occurred exceptionally early (at $2.35 \pm 0.48 \mathrm{DOL}$ ). With regard to the volume of infusion therapy in a more distant terms (14 and 28 days), there was no fundamental difference in the volume of infusion in all groups, which suggests that the principle was the restriction of the infusion therapy in the first 5 days only.
\end{abstract}

Keywords: Patent Ductus Arteriosus, Restrictive Infusion Therapy, Premature Newborns

\section{Introduction}

One of the actual issues of modern neonatal medicine is the reduction of the negative influence of the patent ductus arteriosus (PDA) on morbidity and mortality in preterm infants. The hemodynamically significant PDA (HPDA) have a great value on the development of periventricular leukomalacia (PVL), intraventricular hemorrhage (IVH), bronchopulmonary dysplasia (BPD), necrotizing enterocolitis (NEC), sepsis, retinopathy of prematurity (ROP), which leads to disability in preemies [1].
According to many authors, the time of PDA closure is also an independent factor affecting morbidity and mortality in preterm infants. In a number of publications, we substantiated and proved that delayed PDA closure (after day of life 3), significantly increases the percentage of complications such as BPD, PVL, IVH, NEC, ROP [2].

As we have mentioned earlier [3], among the different ways of PDA management major role played cyclooxygenase (COX) inhibitors, modes of infusion therapy, diuretics. Also important to reduce the negative impact of respiratory support (balanced approach to intubation, early extubation, the use of noninvasive ventilation). 
Indomethacin and ibuprofen have been traditionally used as COX inhibitors. The possibility of using paracetamol for PDA closure is periodically discussing [3, 4], but this way has not been widely accepted as for now. Comparative effectiveness of different COX inhibitors has been described in our resent publications. [5] The therapeutic value of COX inhibitors has no doubts opposed to the restrictive infusion therapy in the maintance of the pharmacological PDA closure.

However, according to the Cohrane review, there is the socalled conservative therapy for the PDA closure, against which include the restriction of infusion therapy only without the COX inhibitors using $[6,15,16]$. Regarding the recommended volume of restrictive infusion therapy, the data vary significantly: from $100-130 \mathrm{ml} / \mathrm{kg} /$ day to $60-80$ $\mathrm{ml} / \mathrm{kg} /$ day in the first $3 \mathrm{DOL}$. The effectiveness of conservative therapy for the closure of hemodynamically significant PDA is $40-45 \%$ and therefore it is not accepted widely according to a number of authors [7]. Some authors believe that only the early surgical clumping of the duct is essential or, lastly, the choice of the COX inhibitor for PDA closure. The reduction of the infusion is often left out of attention [10-16]. Obviously, restrictive infusion therapy for treatment HPDA should be used in combination with COX inhibitors recommended by most authors and editions [10$16]$.

There is also a theory that at the present time there is a clear connection with the volume of infusion and the term of PDA closure. Taking into account the above, we have done a comprehensive research. We studied the impact of the termination of the PDA on morbidity and mortality in preterm infants, as well as the analysis of the effectiveness of various treatment options for PDA closure.

\section{Materials and Methods}

\subsection{Goal}

The main purpose of the study was to establish the expediency, efficiency and safety of using different volumes of infusion in combination with $\mathrm{COX}$ inhibitors and to determine its effect on the timing of the HPDA closure.

Retrospective study of 91 preterm infants received treatment in the intensive care unit of the Regional Children's Clinical Hospital in Dnipropetrovsk in 2012-2017. The research groups were representative of gestational age, gender and weight.

\subsection{Criteria}

Inclusion criteria: gestational age 26-31 weeks, manifestations of respiratory distress syndrome (RDS), HPDA.

Exclusion criteria: IVH grade 3-4, congenital malformation, early onset neonatal sepsis.

Premature infants were discharged to the NICU at DOL 12. The doplerographic echocardiography have been performed during first day staying at the NICU. 100\% of preemies had an open ductus arteriosus. All examined preterm infants in all groups had manifestations of acute respiratory distress syndrome and they were given artificial ventilation of lungs with different settings. After extubation, non-invasive respiratory support was used to complete the transition to spontaneous respiration.

\subsection{Methods}

Systemic and cerebral hemodynamics were assessed with ultrasound examination methods (doplerographic echocardiography, cranial ultrasound with the doplerography) and clinically. All preterm infants included in the study were examined in seven stages. The first stage: observation immediately after discharging to the NICU of the Regional Children's Clinical Hospital in Dnipropetrovsk. The second stage: the 3 day course of the therapy. Subsequent stages were in dynamics at 5, 7, 14 and 28 day course of the therapy respectively.

The boys were 54 (59.3\%), girls were 37 (40.6\%). Weight at birth was $1205.0 \pm 435.0$ grams on average. The all preterm infants who were admitted to the NICU were in severe condition. The main problems were respiratory distress syndrome, patent ductus arteriosus, which conditioned the need for respiratory and inotropic support.

All preterm infants received restrictive infusion therapy of varying degrees, along with COX inhibitors for the PDA closure. It has been noted that the arterial duct is closed at different times.

Depending on the term of PDA closure, preemies were retrospectively divided into two groups:

The first study group - an early closure of the arterial duct (in the first 3 days) - 40 preemies (67\%). The preterm infants had gestational age of $29.0 \pm 1.5$ weeks, weight $1222.2 \pm$ 356.0 grams in average. In the first group the boys were 27 (67.5\%), the girls - $13(32.5 \%)$.

The diameter of the PDA was $2.8 \pm 0.7 \mathrm{~mm}$ in the first examination in the NICU.

The second study group - 20 preterm infants (33\%). Preemies had gestational age of $28.6 \pm 2.2$ weeks, and weight $1218.5 \pm 356.0$ grams in average. In the second group - boys were $9(45 \%)$, and girls $11(55 \%)$. The diameter of the PDA was $3.0 \pm 0.3 \mathrm{~mm}$ in the first examination in the NICU. In the second grope arterial duct was closed in a delayed time (more than 4 days) pharmacologically, or by surgical clapping.

There was no significant difference in sex between the groups. There was no principal difference between the groups in patient's weight.

\subsection{The Therapy of $P D A$}

The therapy of PDA closure included the use of different volumes of restrictive infusion therapy (from 50 to 100 $\mathrm{ml} / \mathrm{kg} /$ day) in combination with $\mathrm{COX}$ inhibitors. Also dobutamine was prescribed in doses 7.5-10 $\mu \mathrm{g} / \mathrm{kg} / \mathrm{min}$ intravenously. COX inhibitors were prescribed according to standard regimens: in the first 3 days - indomethacin orally in doses $0.2 / 0.1 / 0.1 \mathrm{mg} / \mathrm{kg} / \mathrm{day}$. If the preterm infant had 
symptoms of intestinal paresis (this prevented the oral administration of indomethacin), Ibuprofen was administered in a three-day course in doses of $10 / 5 / 5 \mathrm{mg} / \mathrm{kg} /$ day intravenously or in a rectal form at a dose of 20/10/10 $\mathrm{mg} / \mathrm{kg} /$ day.

Thus, in all groups of preterm standard therapy was used for PDA closure.

\section{Results}

\subsection{Volume of Infusion Therapy}

The volume of infusion therapy was restricted in the first group. Preemies received $53.5 \pm 6.4 \mathrm{ml} / \mathrm{kg} /$ day on DOL1 and 2 . From the third day increased urinary excretion, there was an increase in the amount of infusion therapy up to $63.6 \pm 5.6$ $\mathrm{ml} / \mathrm{kg} /$ day, and at day 5 it was raised to $89.7 \pm 6.8 \mathrm{ml} / \mathrm{kg} /$ day.
It should be noted that precisely with the application of this given limited amount of infusion therapy, we observed an early closure of the arterial duct in this group.

Comparing the first and second groups, it should be noted that in the second group there was no strict adherence to the restriction of the volume of infusion therapy (especially in the first 5 days), and we associated the delayed term for the PDA closure of arterial with that fact. In the first group the limit of the volume of infusion therapy were observed more clearly in the first 5 days, and we have the closure of the arterial duct exceptionally early. With regard to the volume of infusion therapy in a more distant terms (14 and 28 days), there were no fundamental differences in the volume of infusion in all groups, which suggests that the principle was the restriction of the infusion therapy in the first 5 days only (Table 1).

Table 1. Volume of infusion therapy ( $\mathrm{ml} / \mathrm{kg} /$ day) in groups at different times $(p<0,05)$.

\begin{tabular}{llllll}
\hline Volume of infusion & Day 1 & Day 3 & Day 5 & Day 7 & Day 14 \\
\hline 1 group, $\mathrm{ml} / \mathrm{kg}$ /day & $53,5 \pm 6,4$ & $63,6 \pm 5,6$ & $89,7 \pm 6,8$ & $110,7 \pm 5,2$ & $131,0 \pm 4,8$ \\
2group, $\mathrm{ml} / \mathrm{kg}$ /day & $71,2 \pm 6,2$ & $85,0 \pm 5,9$ & $99,1 \pm 8,0$ & $116,2 \pm 6,8$ & $136,7 \pm 6,8$ \\
\hline
\end{tabular}

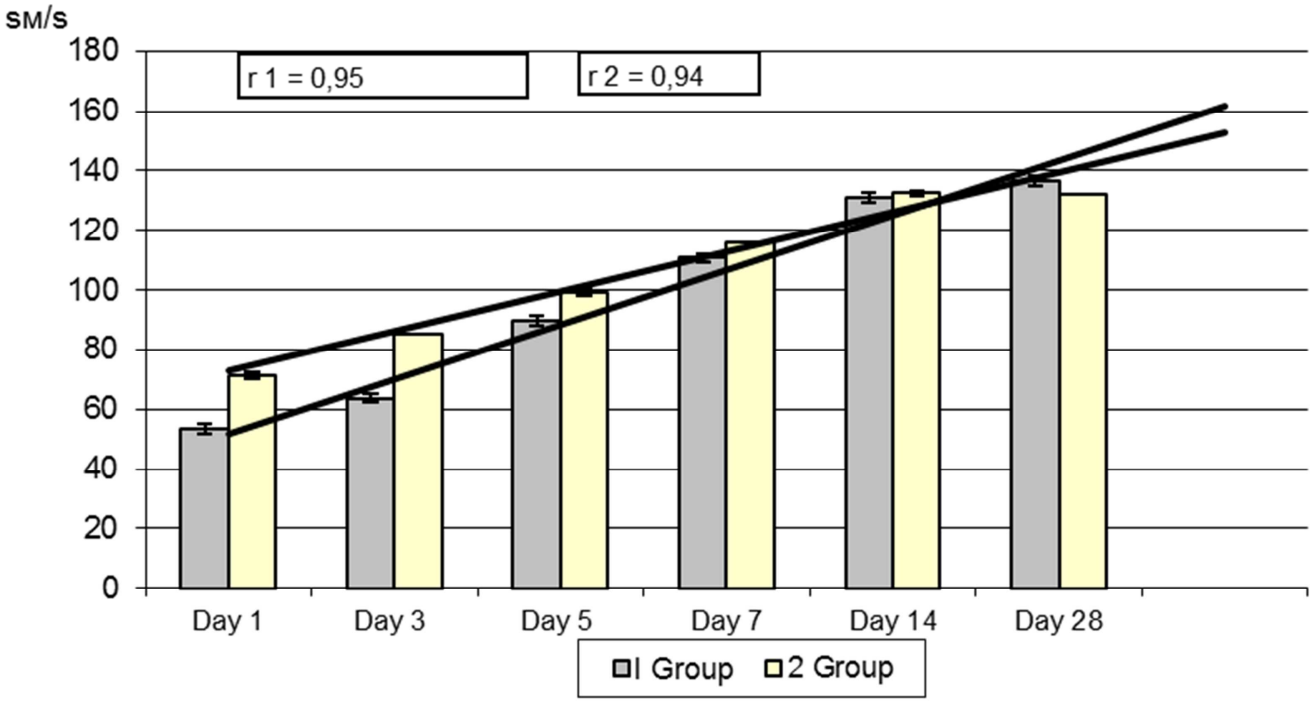

Figure 1. The volume of infusion therapy in 1 and 2 groups at different times.

According to our data, we can conclude that the term of PDA closure in preterm infants as much as possible dependent on the restriction of infusion therapy in the DOL 1 to DOL 5. The recommended volume of infusion the first and second day of life can be considered $53,5 \pm 6,4 \mathrm{ml} / \mathrm{kg} /$ day, and for third day of life is $63,6 \pm 5,6 \mathrm{ml} / \mathrm{kg} /$ day.

\subsection{The Rate of Diuresis}

We analyzed the rate of diuresis. It was a normal 2,2 $\pm 1,2$ $\mathrm{ml} / \mathrm{kg} /$ hour in the first group in DOL1. Diuresis increased significantly on DOL 3 up to $3.6 \pm 1.6 \mathrm{ml} / \mathrm{kg} /$ hour. The maximal rate of urination $6.1 \pm 1.4 \mathrm{ml} / \mathrm{kg} /$ hour was on DOL 5.

Despite most literary sources describe a significant decrease in diuresis up to oligoanuria associated with the COX inhibitors using we do not observed this in our own experience. Diuresis, despite the significant limitation of infusion therapy, was in the normal range for the patient's age in all groups and in all stages of the study (Table 2). In our opinion, the temporal diuresis did not affect the term of arterial duct closure in the subjects.

Table 2. The rate of diuresis in groups ( $\mathrm{ml} / \mathrm{kg} / \mathrm{hour})(p<0,05)$.

\begin{tabular}{llllll}
\hline Diuresis rate & Day 1 & Day 3 & Day 5 & Day 7 & Day 14 \\
\hline 1 group, $\mathrm{ml} / \mathrm{kg} /$ day & $2,2 \pm 1,2$ & $3,6 \pm 1,6$ & $4,1 \pm 1,4$ & $3,9 \pm 1,4$ & $3,9 \pm 1,6$ \\
group, $\mathrm{ml} / \mathrm{kg}$ /day & $2,5 \pm 0,7$ & $3,9 \pm 1,3$ & $3,8 \pm 1,4$ & $3,5 \pm 1,2$ & $3,5 \pm 1,2$ \\
\hline
\end{tabular}




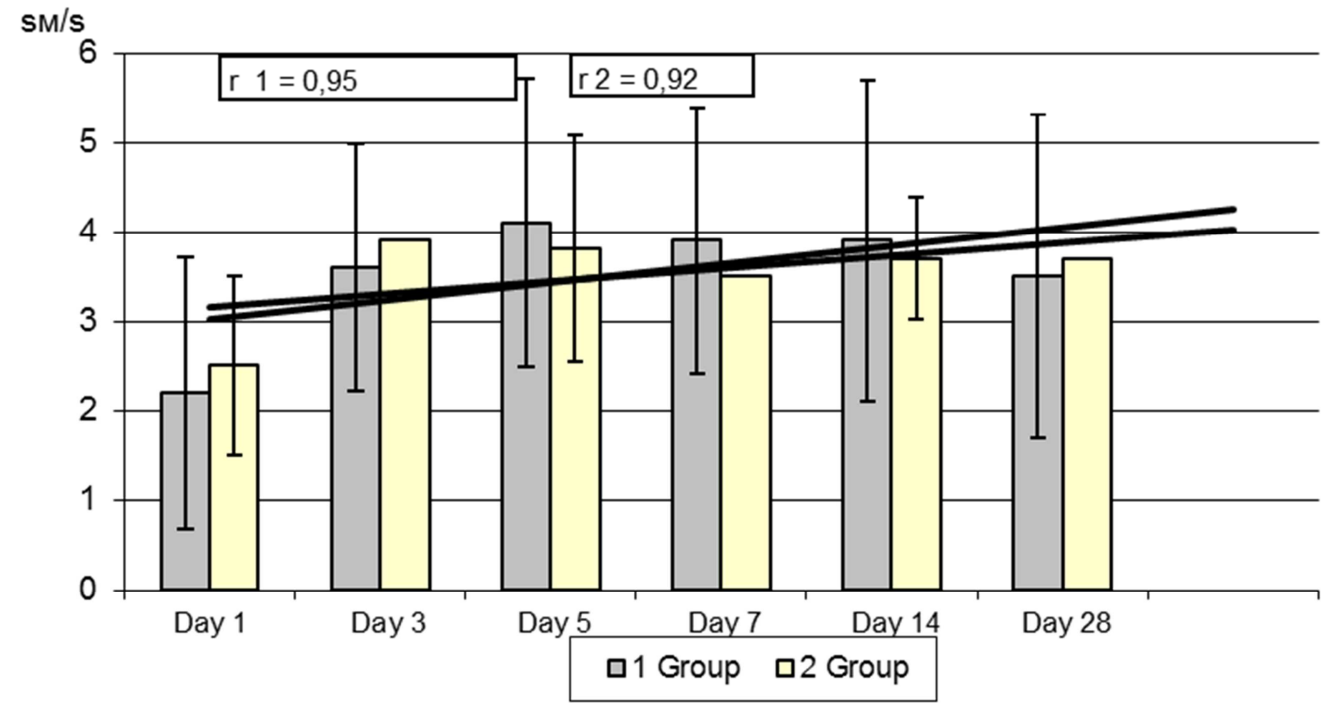

Figure 2. The rate of diuresis in 1 and 2 groups.

\subsection{Body Weight Dynamics}

Regarding the dynamics of body weight, there is a physiological weight loss in the completely healthy newborns in the first 3-4 days. In our subjects, we used restrictive infusion therapy (50-80 $\mathrm{ml} / \mathrm{kg} /$ day) for PDA closure and the patient's weight loss was planned and even desirable. The weight loss observed in the first group was $(-7.1 \% \pm 4.6)$ up to third day of life (Table 3).

Table 3. Body weight dynamics $(p<0,05)$.

\begin{tabular}{llllll}
\hline Body weight dynamics, grams & Day 1 & Day 3 & Day 5 & Day 7 & Day14 \\
\hline 1 Group & $1296,8 \pm 31$ & $-7,1 \pm 4,6$ & $-10,3 \pm 4,3$ & $-10,8 \pm 5,6$ & $-3,8 \pm 3,0$ \\
2 Group & $1215,4 \pm 46$ & $-6,8 \pm 6,6$ & $-9,0 \pm 4,6$ & $-10,5 \pm 6,2$ & $-3,06 \pm 4,6$ \\
\hline
\end{tabular}

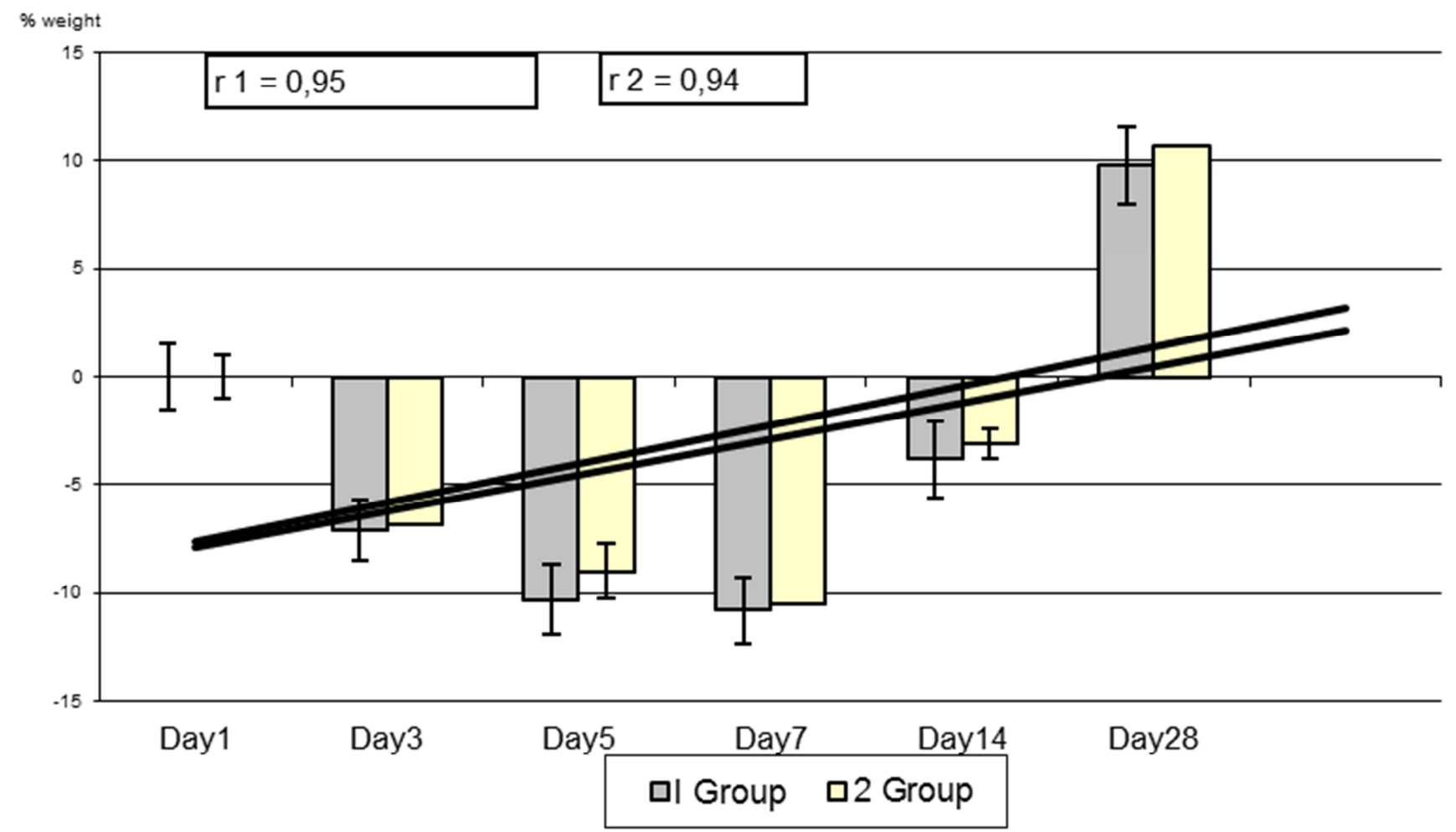

Figure 3. Body weight dynamics

At DOL 5, more negative dynamics of body weight was maintained $(-10.3 \% \pm 4.3)$. The maximum of weight loss was observed at DOL7 and it was $(-10.8 \pm 5.6)$. With the onset of enteral nutrition and increasing in the volume of infusion 
after PDA closure, the body weight deficit reduced to $(-3.8 \%$ $\pm 3.0)$ and on the 28th day of life there was positive dynamics in patient's weight $(+9.8 \% \pm 2,6)$.

It should be noted that the degree of weight loss on DOL 3 , $5,7,14$ was closely related to the term of arterial duct closure. In the second group, the degree of weight loss at all stages was slightly higher than in the first group (see tab. 5).

The arterial duct was closed in all groups in $100 \%$ of cases. Mortality in all groups was $0 \%$. The pharmacological PDA closure was successful in the $100 \%$ (40 preemies) of cases in the first group and in the 70\% (16 preemies) of the second grope (Table 4). In the second group the PDA closure occurred in a delayed period (more than 4 days) at DOL $14.55 \pm 0.56$ on average. In the first group, the PDA closure occurred earlier at DOL $2.35 \pm 0.48$ on average. 6 children (30\%) of the second group had surgical clapping of the arterial duct in a delayed period (on average after 23 days). Recanalization of the arterial duct was found in 6 children (30\%) after DOL 20.

Table 4. Methods and terms of the PDA closure.

\begin{tabular}{lll}
\hline Indicator & 2 Group & 1 Group \\
\hline Diameter of PDA in DOL1 & $3,1 \pm 1,0 \mathrm{~mm}$ & $2,8 \pm 0,5 \mathrm{~mm}$ \\
Terms of PDA closure & $14,55 \pm 0,56 \mathrm{DOL}$ & $2,35 \pm 0,48 \mathrm{DOL}$ \\
Pharmacological PDA closure & $70 \%$ & $100 \%$ \\
Surgical PDA closure & $30 \%$ & $0 \%$ \\
Recanalization of PDA & $30 \%$ & $0 \%$ \\
Indomethacin using as $1^{\text {st }}$ course & $84 \%$ & $85 \%$ \\
Ibuprofen using as $1^{\text {st }}$ course rectal form & $16 \%$ & $15 \%$ \\
Ibuprofen using as $2^{\text {st }}$ course intravenous form & $40 \%$ & $0 \%$ \\
\hline
\end{tabular}

It should be noted that in the first group in all cases the arterial duct was closed pharmacologically and was no PDA recanalization comparing to the second group.

\section{Discussion}

Analyzing the data, we can summarize the following that the mortality rate in all groups was $0 \%$ and the PDA closed in $100 \%$ of cases. The PDA have been closed in the second group with liberal infusion therapy in delayed period after DOL 4 , at $14.55 \pm 0.56$ DOL on average. In the first group with restrictive infusion therapy, the PDA closure occurred earlier at $2.35 \pm 0.48 \mathrm{DOL}$. The 6 children $(30 \%)$ from the second group had surgical clapping of the PDA in a delayed period (on DOL 23 in average). In the first group, in contrast to the second group, there was no case of PDA recanalization, so was no need for surgical treatment. Diuresis was in normal range for age in all groups during the study, despite the significant fluid limitation.

\section{Conclusions}

The combination of COX inhibitor with the strict adherence to the restriction of infusion in the first 5 days is considered to be a principle for the early closure of the arterial duct. The recommended volume of infusion for the successful PDA closure should be - $50 \mathrm{ml} / \mathrm{kg} /$ day for DOL 1 , and $60 \mathrm{ml} / \mathrm{kg} /$ day for DOL 3. The recommended weight loss for the successful PDA closure should be - 7\% for DOL 3 and up to $-10 \%$ for DOL 5 . The rate of diuresis did not affect the term of arterial duct closure in the subjects. Exact adherence to a combination of COX inhibitors and restrictive infusion therapy is more likely to contribute to the pharmacological closure of the ductus arteriosus and reduce the percentage of children who need surgical ligation of the ductus. The use of restrictive therapy and earlier closure of the arterial ductus reduces the percentage of such terrible complications in premature babies as BPD, IVH, NEC, ROP, which decreases the risk of disability in these children. Early pharmacological PDA closure reduces length of hospitalization as well as the cost of treatment.

\section{Perspectives}

The open arterial duct should be pharmacologically closed at early stage with the help of COX inhibitors (indomethacin, ibuprofen) in combination with restrictive infusion therapy. We are planning to study effects of rectal and intravenous forms of paracetamol as COX inhibitors for the pharmacological closure of PDA as the main or second course, but no more than 7 days.

\section{List of Abbreviations}

BPD - bronchopulmonary dysplasia

COX - cyclooxygenase

DOL - day of life

ELBW - extremely low birth weight

GA - gestational age

HPDA - hemodynamically significant patent ductus arteriosus

IVH - intraventricular hemorrhage

MV - mechanical ventilation

NEC - necrotizing enterocolitis

NICU - neonatal intensive care unit

NIV - non-invasive ventilation

NSAIDs - non-steroidal anti-inflammatory drugs

PDA - patent ductus arteriosus

PVL - periventricular leukomalacia

RDS - respiratory distress syndrome

ROP - retinopathy of prematurity

RI - Resistant Index, an index of resistance

VLBW - very low body weight 


\section{References}

[1] Knight D. B. The treatment of patent ductus arteriosus in preterm infants. A review and overview of randomized trials. Semin Neonatol 2001; 6: 63-73.

[2] Evans N. Patent ductus arteriosus in the neonate. Current Paediatrics 2005; 15(5): 381-9.

[3] Hammerman C., Bin-Nun A., Markovitch E. et al. Ductal closure with paracetamol: a surprising new approach to patent ductus arteriosus treatment. Pediatrics. 2011 Dec; 128(6):e1618-21. doi: 10.1542/peds.2011-0359. Epub 2011 Nov 7.

[4] Oncel M. Y., Yurttutan S., Degirmencioglu H. et al. Intravenous paracetamol treatment in the management of patent ductus arteriosus in extremely low birth weight infants. Division of Neonatology, Zekai Tahir Burak Maternity Teaching Hospital, Ankara, Turkey. 2009.

[5] D. Surkov, A. Obolonskiy, O. Kapustina, D. Volkov. Use of rectal ibuprofen for PDA closure in preterm neonates. Pediatric Anesthesia and Critical Care Journal 2014; 2(1):1116.

[6] Surgical closure of patent ductus arteriosus in preterm low birth weight infants // Mandhan P., Brown S., Kukkady A. [et al.] // Congenit Heart Dis. - 2011. - Vol. 4(1). - P. 34 -37.

[7] Tsai E. Withholding and withdrawing artificial nutrition and hydration // Paediatr. Child. Health. - 2011. - Vol. 16(4). - P. 241-242.

[8] Nankervis C. A., Martin E. M., Crane M. L. Implementation of a multidisciplinary guideline-driven approach to the care of the extremely premature infant improved hospital outcomes // Acta Paediatr. - 2010. - Vol. 99. - P. 188-193.
[9] Dent C. L., Schwartz. SM. Postoperative care of the pediatric cardiac surgical patient. In: Cardiovascular Pediatric Critical Illness and Injury // London, United Kingdom: Springer. 2010. - P. 169-179.

[10] Perioperative Fluid Management Strategies in Major Surgery: A Stratified Meta-Analysis // Tomas C., Julia E., Joy R. [et al.] Society of Critical Care Anesthesiologists. - 2012. - P. 640 661.

[11] Edward F. B., Michael J. A. Restricted versus liberal water intake for preventing morbidity and mortality in preterm infants // Cochrane Database Syst Rev. - 2014. - CD000503.

[12] Soni N. British Consensus Guidelines on Intravenous Fluid Therapy for Adult Surgical Patients (GIFTASUP) // Cassandra's view. Anaesthesia. - 2011. - Vol. 64. - P. 235-8.

[13] Meta-analysis of standard, restrictive and supplemental fluid administration in colorectal surgery / Rahbari N. N., Zimmermann J. B., Schmidt T. [et al.] // Br. J. Surg. - 2011. Vol. 96. - P. 331-41.

[14] Nankervis CA, Martin EM, Crane ML. Implementation of a multidisciplinary guideline-driven approach to the care of the extremely premature infant improved hospital outcomes // Acta Paediatr. - 2010. - Vol. 99. - P. 188-193.

[15] Knight D. B. The treatment of patent ductus arteriosus in preterm infants. A review and overview of randomized trials. Semin Neonatol 2001; 6: 63-73.

[16] Vanhaesebrouck S, Zonnenberg I, Vandervoort P, Bruneel E, Van Hoestenberghe MR, Theyskens C. Conservative treatment for patent ductus arteriosus in the preterm. Arch Dis Child Fetal Neonatal Ed. 2007; 92(4):F244 -F247. 